\title{
Different Procedures for Solving Mathematical Word Problems in High School
}

\author{
Javier Gasco $^{1}$, Jose Domingo Villarroel ${ }^{1} \&$ Dani Zuazagoitia ${ }^{2}$ \\ ${ }^{1}$ Department of Didactic of Mathematic and Experimental Sciences, College of Education, University of the \\ Basque Country (Basque Country), Spain \\ ${ }^{2}$ Departament of Analytical Chemistry, University of the Basque Country, Spain \\ Correspondence: Javier Gasco, Department of Didactic of Mathematic and Experimental Sciences, College of \\ Education, University of the Basque Country, Juan Ibáñez de Santo Domingo, 1. 01006 Vitoria-Gasteiz (Araba), \\ Basque Country, Spain. E-mail: javier.gasco@ehu.es
}

Received: March 13, 2014 Accepted: April 15, 2014 Online Published: June 24, 2014

doi:10.5539/ies.v7n7p77 URL: http://dx.doi.org/10.5539/ies.v7n7p77

\begin{abstract}
The teaching and learning of mathematics cannot be understood without considering the resolution of word problems. This kind of problems not only connect mathematical concepts with language (and therefore with reality) but also promote the learning related to other scientific areas. In primary school problems are solved by using basic arithmetic rules and in secondary school, the purpose is to generalize the resolution procedures through putting in practice algebraic procedures which turn to be more effective in terms of resolving word problem. This study attempts to analyse the procedures employed to solve mathematical problems by a sample of students in 9th and 10th grades of High School $(\mathrm{N}=406)$ from the Basque Country (Spain). For this purpose, the procedure used by the students when resolving three mathematical problems was examined and classified in three categories. These categories are related to the utilization of arithmetic rules or, as the case may be, algebraic procedures. The results indicate a significant relationship between the procedure used to solve the problems and educational level of the students. Educational implications of the findings are discussed.
\end{abstract}

Keywords: math education, word problem solving, grade differences, high school

\section{Introduction}

Solving word problems plays a significant role in current mathematics education (Boonen et al., 2013; Timmermans, Van Lieshout, \& Verhoeven, 2007). In this connection, applying abstract mathematical rules when it comes to solving word problems of the daily life is considered a substantial objective in the field of mathematical education.

According to NCTM (2000), "Solving problems is not only a goal of learning mathematics but also a major means of doing so ... By learning problem solving in mathematics, students should acquire ways of thinking, habits of persistence and curiosity, and confidence in unfamiliar situations..." (p. 52). This way, through experiences in solving problems children enhance their skills for strategic thinking while they learn mathematical content (Pape, 2004).

In school context, daily life related problems are usually presented orally and often the information given to tackle a problem blends relevant data with irrelevant information (Scheiter, Gerjets, \& Schuh, 2010). In fact, word problems are broadly used as an educational resource at schools and at universities and this type of activities can be found in the curriculum of mathematics and science from kindergarten level to undergraduate school (Jonassen, 2003).

Recent research draws attention to the importance of the cognitive skills that underlie the capacity for solving word problems. In this regard, the following skills have been reported: the ability to understand a problem (Koedinger \& Nathan, 2004), the capacity to apply an appropriate method of resolution (Gerjets et al., 2004) and the skills to build mental abstract models (Scheiter, Gerjets, \& Schuh, 2010). Some scholars have also mentioned the processing domains linked to the performance in problem solving; for instance, the visual-spatial domain, related to the creation of inner representations through visual schemes (Krawec, 2010) and the linguistic-semantic domain that allows individuals to connect different part of the text in order to reach a solution 
of the problem (Van der Schoot, Bakker Arkema, Horsley, \& Van Lieshout, 2009).

On a separate issue, current research also reports the following difficulties regarding the solving process of word problems (Ng \& Lee, 2009): the lack of understanding of the meaning of the algebraic symbols; the barriers to accurately convert the data provided by natural language into mathematical equations; the incorrect interpretation of the semantic structure of texts and, as a result, the misunderstanding of the relationships between quantities and, finally, the difficulties to bring the semantic evidence from phrases to mathematical equations. These word problems, which are based on the relationship between known and unknown quantities, are commonly referred to as compare word problems (Lewis \& Mayer, 1987; Pape, 2004). The combination between the relationships and the consistency of language provides a significant complexity to solving problems.

Given the complexity of the process of solving problems, different types of strategies for their resolution have been identified (Schoenfeld, 1987). Thus, the novice problem solvers undertake a problem through a superficial reading of the problem; that is to say, an exploratory scrutiny, and, in addition, they do not monitor the process (Pape, 2004). However, the more expert individuals in solving problems are characterised by tackling the problem, firstly, through a deep reading and analysis of the problem and then by finding the solution through different cognitive strategies such as planning, performance and verification (Baroody, Feil, \& Johnson, 2007; Star, 2005, 2007). In this regard, the experts address the problems, firstly, by considering different patterns of resolution and, secondly, they try to find the suitable pattern that can be helpful in the solving of each problem (Lajoie, 2003).

According to the aforementioned research background, the main objective of this study is to identify the procedures that a sample of students in High School uses when it comes to dealing with word problems. The study also attempts to analyze to what extent the procedures used by the students in the first course show some degree of divergence from those that are employed by senior high school students.

To the best of our knowledge, previous research has not addressed the issue of the possible differences between students in different levels of High School in terms of using of different strategies to solve word problems.

\section{Method}

\subsection{Sample}

The sample is comprised of 406 students enrolled in compulsory secondary education levels (14-16 year old). Just under a half of the subjects of the sample are in the final year of secondary education (10th grade, 15-16 year old) and the other individuals are in the 9th grade (14-15 year old). Moreover, the sample turns out to be balanced in terms of sex distribution and, thus, $53.9 \%$ of the individuals are girls. Table 1 accounts for the absolute frequencies of the sample regarding both grade and sex factors.

Table 1. The distribution of the sample according to sex and grade $(\mathrm{N}=406)$

\begin{tabular}{cccc}
\hline Grade & \multicolumn{3}{c}{ Sex } \\
\hline & Girls & Boys & Total \\
\hline 9th & 116 & 95 & 211 \\
10th & 103 & 92 & 195 \\
Total & 219 & 187 & $\mathrm{~N}=406$ \\
\hline
\end{tabular}

All the data were collected on 8 educational centres belonging to the Basque Country (Spanish State), 5 of them are state schools and the other 3 are public schools. The socioeconomic status of the cities where the schools are located is similar.

\subsection{Measures}

The individuals of the sample are asked to solve three mathematical problems. These problems have been also successfully used in previous research (Stacey \& MacGregor, 2000) and they range from lower to higher degree of complexity in terms of its resolution through non-algebraic methods. Thus, the second problem resembles the first one but the students are asked to find three results instead of only two (see Appendix).

The strategies to solve each problem were considered in accordance to the encoding procedure proposed by Khng and Lee (2009) and, accordingly, in this study the following four categories are described: 
- The algebraic category: In the case that the approach to solve the problem is based on one or two unknown quantities and the solution is found by means of one or more equations.

- The arithmetical category: When the problem is tackled by an arithmetic approach; that is to say, without resorting to neither unknown quantities nor equations.

- The mixed category: This is the case when letters are used to resolve the problem but, in essence, the solution is found by an arithmetical procedure.

- The unanswered or unresolved category: when unidentified methods are used or when a problem is not solved.

During the encoding process, both the arithmetical category and the mixed category were considered together within the arithmetical category.

Furthermore, three arithmetic-algebraic word problems were presented to each participant in order to study the problem solving strategies used. In accordance with the methods used to resolve the problems, the individuals of the sample were matched to one of the following three categories:

- G3 or algebraic profile group: The subjects included in this category are characterized by the fact that they solve all problems correctly by an algebraic procedure. Besides, the individuals who find the correct answer by algebraic procedure in two of the three problems but they do not reach the correct answer in the third problem due to a calculation error (in no case a procedural mistake) were also considered in this category.

- G2 or mixed profile group: The individuals included in this category employ both algebraic and arithmetic strategies depending on the problem to be solved. In this way, the students who correctly solve two problems algebraically and, the third one, arithmetically, or vice versa (two problems arithmetically and one algebraically), fall into this category.

- G1 or undefined group: The students in this category do not fit into the aforementioned two profiles due to the lack of using algebraic or arithmetic procedures. Moreover, those students whose at least one answer is considered as unanswered or unresolved are also included in this group.

In short, on the one hand, the students in the G3 group solve problems by algebraic procedures and, on the other hand, the individuals who belong to the G2, use mixed procedures (sometimes these students tackle the problems using algebraic procedures and, other times, by means of arithmetic techniques). Finally, the subjects in G1 group make no or very little use of algebra and, at the same time, they do not master arithmetic techniques.

The aforementioned way to classify the procedure that the students use to solve the word problems emphasizes the usefulness of the algebraic techniques. It is worth noting that this point is consistent with the goals proposed for secondary education which pursue to foster the use of algebraic procedures when it comes to solving mathematical word problems. The arithmetic or heuristic techniques are closely related to the learner's previous experience (Khng \& Lee, 2009) and it is believed that these procedures, very common in Primary School, are not but auxiliary techniques in secondary education, since that in this level the students need to enhance their algebraic thinking.

Moreover, previous research has showed the relevance of the group G2 (Gasco \& Villarroel, 2012). In accordance to this study, many students use arithmetic procedures to solve word problems that are appropriate for this technique but these students employ algebra when tackling difficult problems to be solved by arithmetic procedures.

\subsection{Procedure}

The research protocol undertaken to collect the data for the study was as follows:

Firstly, the objectives and the procedure of the research project were presented and approved by the principal of the schools and, also, by the teachers who were to take part in the study. Then, when the teachers accept to do the exercises, a class hour is agreed to carry them out. The only two conditions of the investigators were: 1) the teaching unit referred to word problems had already been given; and 2) not revealing the nature of the exercises to the participants, that is, not specifying that the problems will be arithmetic-algebraic.

The participants needed between 10 and 25 minutes to complete the problems. In regard of personal information requested, the sex and the date of birth of each student was the only data asked to.

\subsection{Statistical Analysis}

The level of significance used in the investigation was $\mathrm{p}<0.05$ and the statistical work was done using the PASW Statistics 18 software. 


\section{Results}

Table 2 presents the absolute frequencies of each of the three procedures to solve word problems considered in the study, related to the academic school year of the participants. The differences shown in this table are significant $\left(\mathrm{X}^{2}(2, \mathrm{~N}=406)=8.63 ; \mathrm{p}<.05\right)$.

Table 2. The absolute frequencies of the procedures to solve word problems regarding the academic school year (grade) of the participants $(\mathrm{N}=406)$

\begin{tabular}{cccc}
\hline Category & \multicolumn{3}{c}{ Grade } \\
\hline & 9 th & 10 th & Total \\
G1 & 70 & 62 & 132 \\
G2 & 46 & 23 & 46 \\
G3 & 95 & 110 & 95 \\
Total & 211 & 195 & 406 \\
\hline G1 = The undefined group; G2 $=$ The mixed profile group; G3 = The algebraic profile group
\end{tabular}

Table 3 shows the percentages of the three types of procedures considered in this study in connection with the grade of the students.

Table 3. The percentages of the procedures to solve word problems as regards the grade of the participants

\begin{tabular}{ccc}
\hline \multicolumn{2}{c}{ Category } & Grade \\
\hline G1 & 9 th & 10 th \\
G2 & $33 \%$ & $32 \%$ \\
G3 & $22 \%$ & $12 \%$ \\
G1 = The undefined group; G2 = The mixed profile group; G3 = The algebraic profile group
\end{tabular}

Figure 1 illustrates the percentages of each of the three types of procedures analysed in this study linked to the grade of the students. 


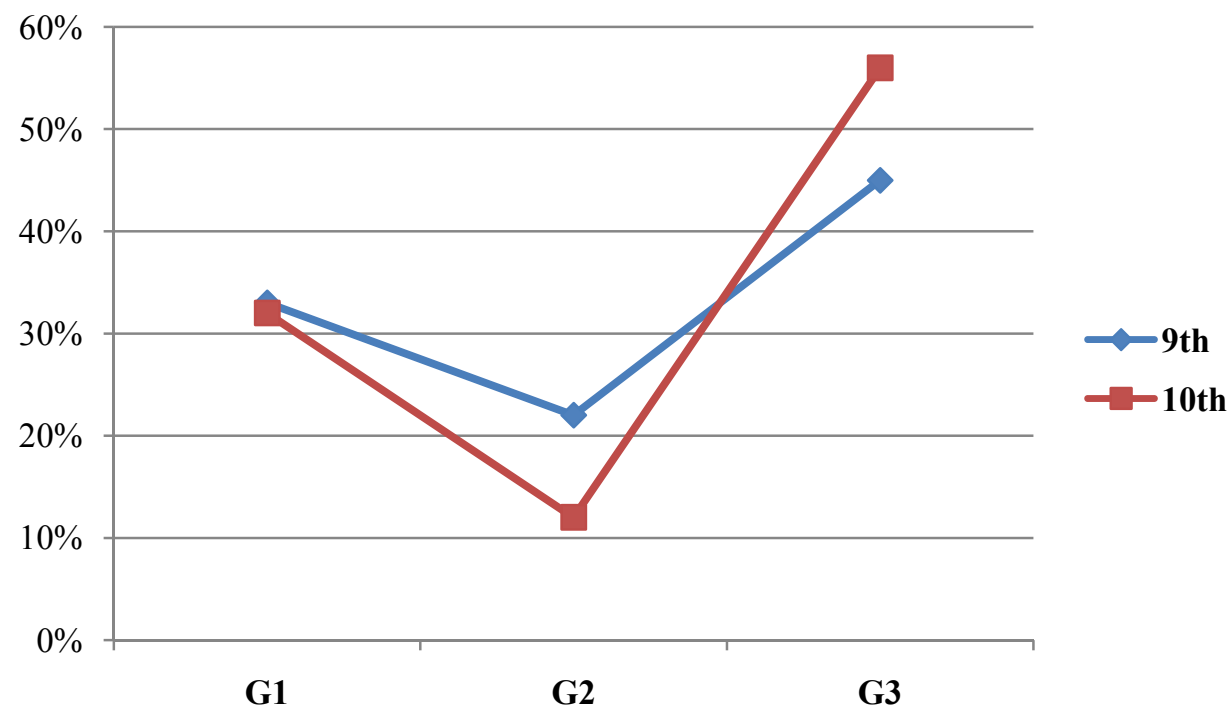

G1 = The undefined group; $\mathrm{G} 2$ = The mixed profile group; $\mathrm{G} 3=$ The algebraic profile group

Figure 1. Percentages of the procedures to solve word problems as regards the grade of the participants

The previously presented data points out that the frequency of the G2 procedure is lower in 10th than in 9th grade. Furthermore the figures also indicate that the G3 procedure shows the contrary tendency; that is to say, this procedure is more often used by the older students than by their younger classmates.

This idea is coherent with the assumption that the use of the algebraic procedures become more common as the students moves to higher educational grades and, as a result, the older students are less prone to tackle mathematical problems by mixed procedures (arithmetic or algebraic, depending on the type of problem).

\section{Discussion}

The presented results indicate that the use of algebra in solving problems is higher in the 10th year of High School than in 9th. In other words, the frequency of the G3 resolution group, which is related to an algebraic profile, is much more frequent in 10th than in 9th grade. In both courses the percentage of students belonging to the undefined profile resolution group (G1) is quite similar. As noted previously, this group is characterized by not solving the problems by algebraic or arithmetic procedures.

Regarding the G2 group, the results point out that the frequency of this category decreases from 9th to 10th grade, the same extent as the G3 category becomes more frequent. It is worth noting that the G2 group is comprised of those students who employ algebraic and arithmetic procedures, according to how the problem proposed is.

Undoubtedly, mathematics is a significant subject in secondary education and related to this area, the development of the skills for problem solving is considered a remarkable objective for this educational level.

Concerning the issue of the study of how the skills for solving arithmetic-algebraic problems evolve from 9th to 10th of High School, little research has been undertaken to examine whether there is any difference between these levels in terms of the resolution procedures preferably used.

In this connection, the presented evidence is coherent with the assumption that as the students' academic training progresses from grade to grade a more systematic use of algebra is boosted, possibly owing to the fact that more difficult problems (such as problems with multiple variables or quadratic equations) are to be tackled in math courses.

The substantial importance that mixed resolution category has in 9th leads to introduce the heuristic procedures which are linked to not rigorous techniques to resolve problems, such as trial and error, empirical rules, diagrams, etc. This methodology to deal with mathematical problem is considered as an arithmetic procedure and the mathematical education curriculum put into practice in many countries points out these methods among those to be mastered with regard to solving mathematical problems. 
The main contribution of this research is the analysis of the duality related to the mixed solving group profile. In this context, Jennings and Dunne (1996) regard to a reduction of the complexity of the problems and an extension of the use of informal or arithmetic techniques in order to facilitate the homework that students have to do. Stacey and MacGregor (2000) indicate that "Instead of using simple problems merely to illustrate methods essential for harder problems, and moving students on to problems that require algebra, teachers had allowed students to continue solving simple problems using intuitive, non-algebraic methods" (p. 164).

In line with the above-mentioned thinking, Khng and Lee (2009) point out that the flexibility to solve word problems may not be a good option in terms of the capacity for solving them. These authors consider that the persistence in the use of arithmetic strategies may be an intrusion when it comes to fostering the use of algebraic procedures, given that the use of symbolic language linked to algebra is an essential stage in the evolvement towards the understanding of advanced mathematics.

The arithmetic techniques for problem solving are introduced in primary education and they are a prelude to the algebraic procedures which are mainly introduced in secondary education. According to Stacey and MacGregor (2000), the initial experience with arithmetic procedures that students have in primary education, leads to "a compulsion to calculate" which makes students be more prone to work with known values than to the use of unknowns. As a result, this tendency may difficult the use of algebraic strategies in terms of searching, selecting and naming the appropriate unknowns.

$\mathrm{Ng}$ (2003) also points out that the persistence of predilection that secondary students show to use the arithmetic reasoning is an obstacle to internalize the concept of equation which is an essential tool in the process of algebraic resolution (Charbonneau, 1996; Stacey \& MacGregor, 1997; Khng \& Lee, 2009).

In view of all that has been set out above, the use of algebra should be prioritized in secondary education and the heuristics techniques should be considered a significant goal only in primary education. The results presented in this study are consistent with this consideration, given that the older students of the sample turn out to be more prone to the use of algebraic procedures.

In this regard, it is worth noting that the use of the mixed techniques become less common among the older students of the sample and this issue is also coherent with the assumption that as the students move to the higher levels of secondary education, they become more proficiency in the use of algebraic procedures and, also, more aware of the interest that algebra has when it comes to solving difficult mathematical problems.

Finally, it is also noteworthy that, as some studies point out (Deulofeu, Figueiras, \& Pujol, 2011), the heuristics techniques are the basic introduction of the understanding of algebra and in this regard, they are necessary part of the curriculum of primary education. However, concerning secondary education, the heuristics and arithmetical procedures should be considered as auxiliary techniques for problem solving which students should use to achieve the objective of the learning of algebra.

\section{References}

Baroody, A., Feil, Y., \& Johnson, A. R. (2007). An alternative reconceptualization of procedural and conceptual knowledge. Journal for Research in Mathematics Education, 38, 115-131.

Boonen, A. J., van der Schoot, M., van Wesel, F., de Vries, M. H., \& Jolles, J. (2013). What underlies successful word problem solving? A path analysis in sixth grade students. Contemporary Educational Psychology, 38(3), 271-279. http://dx.doi.org/ 10.1016/j.cedpsych.2013.05.001

Charbonneau, L. (1996). From Euclid to Descartes: Algebra and its relation to geometry. In N. Bednarz, C. Kieran, \& L. Lee (Eds.), Approaches to algebra: Perspectives for research and teaching (pp. 15-37). Dordrecht: Kluwer Academic Publishers. http://dx.doi.org/10.1007/978-94-009-1732-3_2

Deulofeu, J., Figueiras, L., \& Pujol, R. (2011). De lo previsible a lo inesperado en un contexto de resolución de problemas. Uno, 58, 84-97.

Gascó, J., \& Villarroel, T. (2012). Algebraic problem solving and learning strategies in compulsory secondary education. Procedia-Social and Behavioral Sciences, 46, 612-616. http://dx.doi.org/10.1016/j.sbspro.2012.05.172

Gerjets, P., Scheiter, K., \& Catrambone, R. (2004). Designing instructional examples to reduce intrinsic cognitive load: Molar versus modular presentation of solution procedures. Instructional Science, 32, 33-58. http://dx.doi.org/10.1023/B:TRUC.0000021809.10236.71

Hamid, S., Hayati, M., Shahrill, M., Matzin, R., Mahalle, S., \& Mundia, L. (2013). Barriers to Mathematics Achievement in Brunei Secondary School Students: Insights into the Roles of Mathematics Anxiety, 
Self-Esteem, Proactive Coping, and Test Stress. International Education Studies, 6(11), 1-14.

Jennings, S., \& Dunne, R. (1996). A critical appraisal of the national curriculum by comparison with the french experience. Teaching Mathematics and Its Applications, 15(2), 49-55. http://dx.doi.org/10.1093/teamat/15.2.49

Jonassen, D. H. (2003). Designing research-based instruction for story problems. Educational Psychology Review, 15, 267-296. http://dx.doi.org/10.1023/A:1024648217919

Khng, K. H., \& Lee, K. (2009). Inhibition interference from prior knowledge: Arithmetic intrusion in algebra word problem solving. Learning and Individual Differences, 19, 262-268. http://dx.doi.org/10.1016/j.lindif.2009.01.004

Koedinger, K. R., \& Nathan, M. J. (2004). The real story behind story problems: Effects of representations on quantitative reasoning. The Journal of the Learning Sciences, 13, 129-164. http://dx.doi.org/10.1207/s15327809j1s1302_1

Krawec, J. L. (2010). Problem representation and mathematical problem solving of students with varying abilities (Doctoral dissertation, University of Miami, Miami).

Lajoie, S. P. (2003). Transitions and trajectories for studies of expertise. Educational Researcher, 32(8), 21-25. http://dx.doi.org/10.3102/0013189X032008021

Lewis, A. B., \& Mayer, R. E. (1987). Student's miscomprehension of relational statements in arithmetic word problem. Journal of Educational Psychology, 79, 363-371. http://dx.doi.org/10.1037/0022-0663.79.4.363

National Council of Teachers of Mathematics. (2000). Principles and standars for school mathematics. Reston, VA: Author.

Ng, S. F. (2003). How secondary two express stream students used algebra and the model method to solve problems. The Mathematics Educator, 7(1), 1-17.

Ng, S. F., \& Lee, K. (2009). The model method: Singapore children's tool for representing and solving algebraic word problems. Journal for Research in Mathematics Education, 40(3), 282-313.

Pape, S. J. (2004). Middle school children's problem-solving behavior: A cognitive analysis from a reading comprehension perspective. Journal for Research in Mathematics Education, 35(3), 187-219. http://dx.doi.org/10.2307/30034912

Scheiter, K., Gerjets, P., \& Schuh, J. (2010). The acquisition of problem-solving skills in mathematics: How animations can aid understanding of structural problem features and solution procedures. Instructional Science, 38(5), 487-502. http://dx.doi.org/10.1007/s11251-009-9114-9

Schoenfeld, A. (1987). What's all the fuss about metacognition? In A. Schoenfeld (Ed.), Cognitive science and mathematics education (pp. 189-215). Hillsdale, NJ: Lawrence Erlbaum Associates.

Stacey, K., \& MacGregor M. (2000). Learning the algebraic method of solving problems. Journal of Mathematical Behaviour, 18(2), 149-167. http://dx.doi.org/10.1016/S0732-3123(99)00026-7

Stacey, K., \& MacGregor, M. (1997). Building foundations for algebra. Mathematics in the Middle School, 2(4), 253-260.

Star, J. R. (2005). Reconceptualizing procedural knowledge. Journal for Research in Mathematics Education, 36, 404-411.

Star, J. R. (2007). Foregrounding procedural knowledge. Journal for Research in Mathematics Education, 38, 132-135.

Timmermans, R. E., Van Lieshout, E. D. C. M., \& Verhoeven, L. (2007). Gender related effects of contemporary math instruction for low performers on problem solving behavior. Learning and Instruction, 17, 42-54. http://dx.doi.org/10.1016/j.learninstruc.2006.11.005

Van der Schoot, M., Bakker Arkema, A. H., Horsley, T. M., \& Van Lieshout, E. D. C. M. (2009). The consistency effect depends on markedness in less successful but not successful problem solvers: An eye movement study in primary school children. Contemporary Educational Psychology, 34, 58-66. http://dx.doi.org/10.1016/j.cedpsych.2008.07.002 


\section{Appendix}

Word problems (Stacey \& MacGregor, 2000):

1) Some money is shared between Mark and Jan so that Mark gets $\$ 5$ more than Jane gets. The money to be shared is $\$ 47$. How much money do Mark and Jane get?

2) A bus took students on a 3-day tour. The distance traveled on Day 2 was $85 \mathrm{Km}$ farther than on Day 1 . The distance traveled on Day 3 was $125 \mathrm{Km}$ farther than on Day 1 . The total distance was $1410 \mathrm{Km}$. How much distance does travel each day?

3) I think of a number, multiply it by 8 , subtract 3 , and then divide by 3 . The result is twice the number I first thought of. What was the number?

\section{Copyrights}

Copyright for this article is retained by the author(s), with first publication rights granted to the journal.

This is an open-access article distributed under the terms and conditions of the Creative Commons Attribution license (http://creativecommons.org/licenses/by/3.0/). 